\title{
The Relationship Between Early and Senior Level Participation in International Women's and Men's Handball
}

\author{
by \\ Christian Thue Bjørndal ${ }^{1}$, Live Steinnes Luteberget ${ }^{2}$, Simen Holm ${ }^{1}$
}

\begin{abstract}
International competitions at the youth elite level have become an important part of attempts to identify, foster and develop sporting talent. However, sports science scholars disagree strongly about the value and importance of such competitions because little is known about the relationship between early performance, at both the team and individual level, and later success in adult elite sports. The first aim of this study was therefore to explore the relationship between international match experience at the youth international team level and subsequent match experience at the junior and the senior international team levels. The second aim of this study was to explore the relationship between youth national team results and subsequent junior and senior national team results in international competitions. The individual-level analysis was based on official match participation statistics of all Norwegian handball players with either youth, junior and/or senior national team experience $(n=657)$ between the years 1993 and 2017. The team level analysis was based on team result rankings from the handball European and World Championships at the youth, junior and senior national team levels during this period. Statistical analysis at the individual level showed a significant difference between those handball players who did and did not have international match exposure at the youth and junior levels, and the number of matches they played at the senior international team level. No to weak correlations were found between the number of matches played at the youth, junior and senior international team levels. Statistical analysis at the team level showed a strong correlation between result rankings at the youth, junior and senior international team levels. Collectively, these findings suggest that having youth and junior international experience is strongly associated with the number of matches played at the senior international level. However, the number of matches played at the youth and junior international levels does not appear to determine success or predict which players will or will not achieve success at the senior international level.
\end{abstract}

Key words: athlete development, talent identification, national squads, elite sport systems, handball.

\section{Introduction}

It has been suggested that formal talent identification and development programmes are the key organisational pillars of successful elite sports systems (De Bosscher et al., 2006). Most attempts to produce and enhance high-level athletic performance are normative and rooted in assumptions that talented athletes can be detected early in their sporting careers. It is argued that if talented athletes are given additional resources, they will ascend towards top-level adult performance (Bailey, 2007). The Ericsson et al.'s
(1993) seminal study of expert performance offers a strong contrary argument to the notion that innate talent can lead to early talent identification, and suggests instead that expertise is acquired through intensive engagement in deliberate practice. Ironically, both belief in the importance of innate talent and belief in deliberate practice as a key pre-requisite for expertise, have resulted in elite sport policies that are similar, namely, to facilitate more talent development initiatives for a selected few. Many sport organisations have

1 - Department of Coaching and Psychology, The Norwegian School of Sport Sciences, Oslo, Norway.

2 - Department of Physical Performance, The Norwegian School of Sport Sciences, Oslo, Norway. 
therefore created incentives for athletes to specialise in a single sport at young ages, for example, through the introduction of international youth competitions.

International competitions at the youth elite level have become an important part of programmes and are part of attempts to identify, foster and develop sporting talent in elite development systems. According to DiFiori et al. (2014), international team memberships may lead to athletes feeling greater pressure to begin highintensity training at a younger age. However, the relationship between early performance, at both the team and individual level, and success in adult elite sports, is unclear (Bailey and Collins, 2013), and there is little among sports science scholars about the value and importance of such programmes. One explanation for the lack of coherence between early performance and later success might be ascribed to the potential negative consequences of early specialisation, such as overuse injuries, burn-out and drop-out from sports (Myer et al., 2015). The term "elite development 'system' ", as Andersen et al. (2015) suggest, may "simply be a description of the interconnection between established practices, with little regard for efficiency and effectiveness and with little attempt to provide a foundation for the system based on research and evidence". Studies of handball players, for example, have shown that players' progress through national squads can be variable (Silva et al., 2015). To produce a better understanding of the quality, value and preferred characteristics of international competitions at the youth elite level, closer empirical examination is needed of talent identification and development programmes.

Handball is a complex and physically demanding team ball game and an Olympic sport (Wagner et al., 2014). It is an intermittent invasion game characterised by repeated high-intensity running and throwing, accelerations and decelerations, powerful changes of directions, and full-body contact (Luteberget and Spencer, 2017; Povoas et al., 2014). Youth and junior international team activities have been shown to positively influence athlete development in Norwegian handball, and can provide an important arena for high quality practice and competition (Bjørndal et al., 2015). However, in both youth and senior elite handball, playing handball is associated with a high risk of injuries, both chronic and acute (Steffen and Engebretsen, 2010). For players involved in youth and junior international team activities, the risk of injuries can be even higher, especially among those identified as being the most talented athletes (Bahr, 2014). Injuries could therefore be one potential factor for talented players to drop out of their sport before they reach their full potential (Malina, 2010). More knowledge is needed within specific sporting contexts to understand the complex relationship between early performances and adult success, and the role of international youth competitions in the development of athletes.

The first aim of this study was therefore to explore the relationship in women's and men's handball between international match experience at the youth, junior and senior international team level. The second aim was to explore the relationship in international women's and men's handball between results in youth, junior and senior national team competitions. This study also addresses the need for more studies of athlete development in women's sport (Costello et al., 2014). Importantly, individual progression at the international team level within the distinct context of Norwegian handball was contextualised. The knowledge and insights gained, however, have the potential to influence policy-decisions at both the international and the national level, in terms of how youth and junior national teams can be more effectively organised to produce the intended long-term outcomes of athlete development.

\section{Methods}

Participants and the context

The sample of this study included: (a) Norwegian female and male athletes who have played matches at the youth, junior and/or senior international team levels, and (b) team result rankings at the youth, junior and senior international level in women's and men's handball.

Norwegian handball is rooted in the values of volunteerism, decentralisation and egalitarianism which characterise the Scandinavian sports model (Ronglan, 2014). The organisational structure of the talent development in Norwegian handball includes multiple 
autonomous parties, such as clubs, sport schools, regional federation-level talent development activities, and youth and junior international team activities. In the context of Norway, no party has instructional authority over others, and no single party has sole responsibility for talent development.

In both women's and men's handball in Norway, the player development model of the National Handball Federation is broad-based: as many as one-third of all youth handball players participate in different talent development initiatives during their early adolescence (Bjørndal et al., 2015). Athletes are first selected to talent development initiatives at a relatively late age (13+ years). The broad-based talent development initiatives in Norway vary in quality. Players are not officially moved from one level to another and there are no formal threshold measures: it is not unusual for an athlete to return to the talent route after de-selection, and the age at which early specialisation is allowed is partly limited through the formal regulations governing child sport. Although the selections made for the Norwegian international handball team can be rotated, monthly five-day training camps are common and many international team players participate in all four of the annual international handball championships throughout their fiveyear period on their national team. Athletes selected to the youth or junior international teams remain part of their club teams and sport school programmes, and also participate in the regional talent development activities.

The European Handball Federation and the International Handball Federation each organise the European Championships and World Championships once every two years, respectively. Both tournaments are played during Europe's summer holidays and the teams must qualify to take part. Each international team is based on a two-year age category: players born in the same two-year period play together throughout their international team careers.

Procedures

Individual match participation statistics (Table 1) were obtained with permission from the Norwegian Handball Federation. The database provided the gender of the players and the number of matches played at the youth, junior and senior international team levels for each of the players. The individual level analysis included all female $(n=318)$ and male players $(n=339)$ who had participated in the official matches of the youth, junior and/or senior international teams, and who were born in the period from 1986 to 1999. Although official statistics were used, all the player's names were anonymised in compliance with the study's ethical requirements.

The handball team results were obtained from the official online archives of the European Handball Federation (retrieved from www.eurohandball.com) and the International Handball Federation (retrieved from http://www.ihf.info/en-

us/ihfcompetitions/competitionsarchive.aspx). All European and World championship matches played at the youth, junior, and senior levels between the years 1993 and 2017 were included in the team level analysis. This period was chosen because it provided a sufficient and representative quantity of data for analysis. We chose not to include handball data from the European Youth Olympic Festival, the Youth Olympic Games, and the Olympic Games in our data analyses because these competitions are relatively new additions to the youth and junior level international championships. The database included team result rankings for each championship level in woman's and men's handball.

Statistical analysis

Player data at the individual level in women's and men's handball were divided between those who had or had not played official matches at the youth, junior and senior international team levels. We first used a MannWhitney $U$ Test to determine if there were significant differences in terms of the number of matches between players who had played or had not played matches at: (a) the youth international level and the total number of matches at the junior international level; (b) the youth international level and the total number of matches at the senior international level; and (c) the junior international level and the total number of matches at the senior international level.

Secondly, a Spearman's Rank-Order Correlation was applied to assess the relationship between the number of international matches from the youth to junior level; from the youth level to the senior level; and, finally, from the junior to the senior international level in both 
women's and men's handball. A preliminary analysis across all the categories showed monotonic relationships, as assessed by visual inspections of the scatterplots.

The team-level data was organised manually. Teams that were placed $1^{\text {st }}$ to $10^{\text {th }}$ in any of the championships between 1993 and 2017 were included in the study (Serbia and Montenegro were given the points of the former Republic of Yugoslavia). They were given an inverted score: the first place was given 10 points, the second place was given 9 points, and so on. After all the scores of each international team at the youth, junior and senior levels were added together, a Spearman Rank-Order Correlation analysis was applied. The preliminary analysis, as assessed by visual inspections of the scatterplots across all categories, showed monotonic relationships.

The statistical analyses were undertaken using the program IBM SPSS statistics v24. The Spearman Rank-Order Correlations were categorised as follows: $<0.30=$ no correlation, 0.30-0.49 = weak correlation, $0.50-0.69=$ moderate correlation, $0.70-0.99=$ strong correlation, and 1.0 $=$ perfect correlation.

\section{Results}

The results of this study show that about $50 \%$ of players progressed from the youth to the junior international teams in both women's and men's handball in Norway, and that approximately $15 \%$ of players progressed from the youth teams to the senior national teams (Table 2). $19 \%$ of female players and $27.9 \%$ of male players progressed from the junior international level to the senior international team. Conversely, between $71-80 \%$ of the female and male junior national team players had gained competitive match experience at the youth national team level. $80 \%$ of female and $92.7 \%$ of male players at the senior national team level had gained competitive match experience at the junior national team level, and $82-84 \%$ of both female and male players had experience at the youth national team level.

A Mann-Whitney $U$ test was applied to determine if differences were evident in the number of international team matches played in the junior and senior categories across players with and without match experience from another team level. The distributions across all categories were visually inspected and found to be similar.

In Norwegian women's handball, the number of junior international team matches was significantly higher among players who had played in youth international team matches compared to those players who had not, $U=9366$, $z=2.278, p=23$; the number of senior international team matches was significantly higher among players who had played in junior international team matches compared to those players without such experience, $U=9085, z=$ 5.420, $p=0.0005$. In Norwegian men's handball, the number of junior international team matches was significantly higher among players who had played in youth international team matches compared to those players who had not, $U=7085$, $z=2.001, p=45,000$; the number of senior international team matches was significantly higher among players who had played in youth international team matches compared to those players who had not, $U=4880, z=-2.944, p=$ 3,000 ; the number of senior international team matches was significantly higher among players who had played in junior international team matches compared to those players without such experience, $U=10622, z=-6.345, p=0.0005$, using an exact sampling distribution for $U$ (Dineen and Blakesley, 1973).

The moderate correlation between the number of matches played at junior and senior international levels for male players was the highest correlation found. The Spearman's RankOrder Correlation showed higher $\mathrm{r}_{\mathrm{s}}$ values for men compared to women (Table 3) in all comparisons indicating that the number of matches played at each level was more strongly associated with future success in men's international handball.

The ranks of the different national teams at the youth, junior and senior international team levels, for both men and women, are shown in Table 4. Figure 1 is in an X-Y plot showing the total points given to the teams playing between different team levels. The Spearman's Rank-Order Correlation for the team level analyses showed high correlations $\left(r_{s}>0.80\right)$ for all comparisons, both for men and women (Table 5). 


\begin{tabular}{|c|c|c|c|c|c|}
\hline \multicolumn{6}{|c|}{$\begin{array}{l}\text { Table } \mathbf{1} \\
\text { The list of players included in the individual analysis of the relationship between } \\
\text { the number of matches played at different team levels and the characteristics of the players. }\end{array}$} \\
\hline & & $\begin{array}{c}\text { Number of } \\
\text { players }\end{array}$ & $\begin{array}{c}\text { Mean number } \\
\text { of matches }\end{array}$ & Min & Max \\
\hline \multirow{3}{*}{ Women } & Youth & 256 & 17.1 & 1 & 51 \\
\hline & Junior & 190 & 15.7 & 1 & 38 \\
\hline & Senior & 45 & 34 & 1 & 209 \\
\hline \multirow{3}{*}{ Men } & Youth & 299 & 15.2 & 1 & 56 \\
\hline & Junior & 182 & 14.9 & 1 & 47 \\
\hline & Senior & 55 & 9.2 & 1 & 127 \\
\hline
\end{tabular}

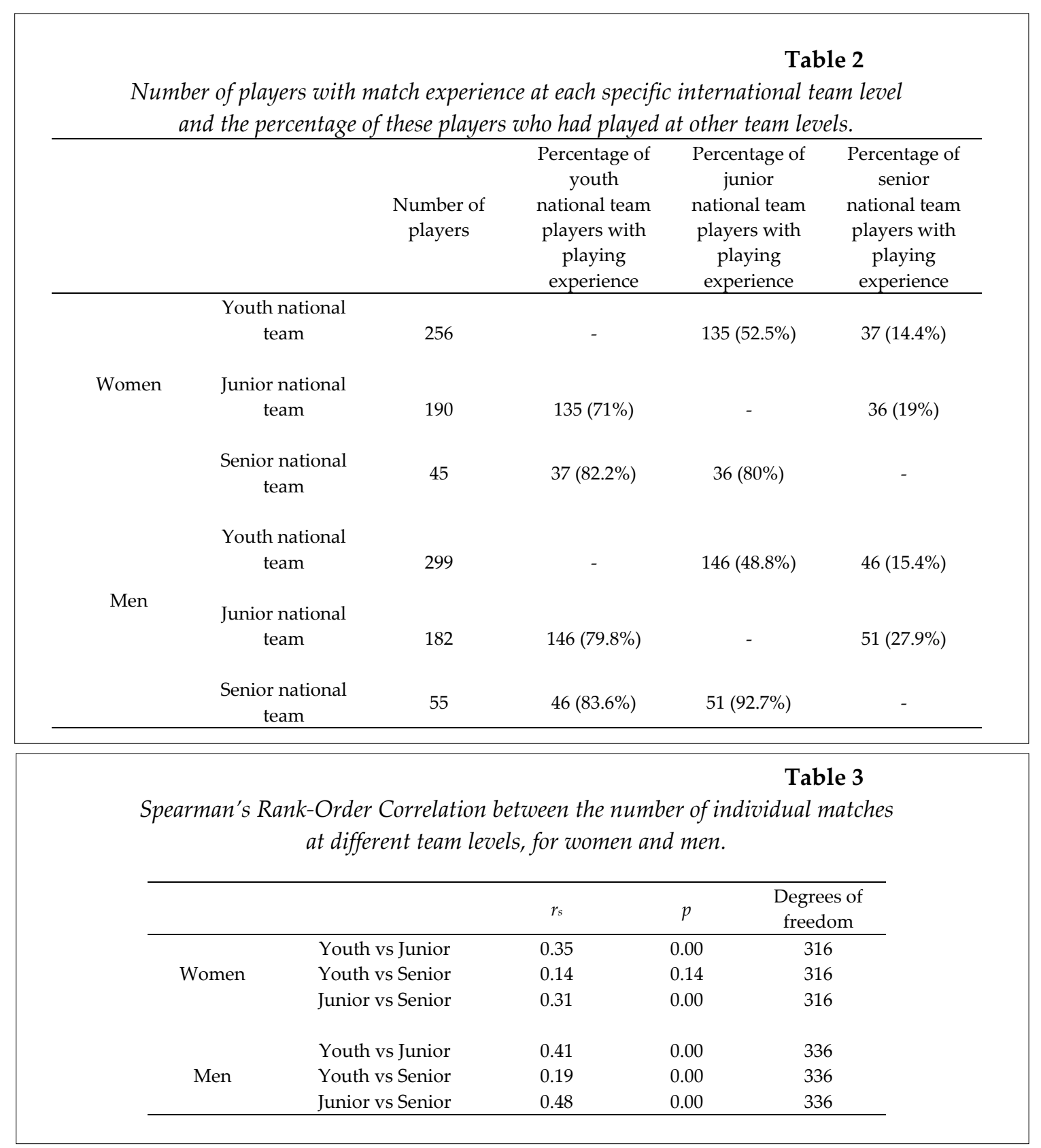




\begin{tabular}{|c|c|c|c|c|c|c|c|}
\hline \multirow[b]{3}{*}{ Team } & ks of dif & erent te & ms acro & \multicolumn{4}{|c|}{$\begin{array}{l}\text { Table } 4 \\
\text { women and men. }\end{array}$} \\
\hline & \multicolumn{3}{|c|}{ Women } & \multirow[b]{2}{*}{ Team } & \multicolumn{3}{|c|}{$\underline{\text { Men }}$} \\
\hline & Youth & Junior & Senior & & Youth & Junior & Senior \\
\hline Norway & 5 & 4 & 1 & France & 6 & 5 & 1 \\
\hline Denmark & 2 & 2 & 2 & Spain & 2 & 2 & 2 \\
\hline Russia & 1 & 1 & 3 & Croatia & 3 & 9 & 3 \\
\hline Hungary & 4 & 3 & 4 & Sweden & 5 & 4 & 4 \\
\hline France & 6 & 7 & 5 & Germany & 4 & 3 & 5 \\
\hline Germany & 8 & 6 & 6 & Denmark & 1 & 1 & 6 \\
\hline Romania & 3 & 5 & 7 & Russia & 12 & 10 & 7 \\
\hline Sweden & 7 & 8 & 8 & Serbia & 8 & 7 & 8 \\
\hline Spain & 9 & 9 & 9 & Poland & 15 & 13.5 & 9 \\
\hline Montenegro & 15 & 14 & 10 & Hungary & 11 & 11 & 10 \\
\hline Austria & 18.5 & 18 & 11 & Iceland & 9.5 & 18 & 11 \\
\hline Korea & 12 & 10 & 12 & Slovenia & 7 & 6 & 12 \\
\hline Serbia & 13 & 13 & 13 & Norway & 13 & 15 & 13 \\
\hline Croatia & 11 & 11 & 14 & Egypt & 18 & 8 & 14 \\
\hline Netherlands & 10 & 12 & 15 & Czech Republic & 20 & 19 & 15 \\
\hline Ukraine & 27 & 22 & 16 & Qatar & 24.5 & 29 & 16 \\
\hline Poland & 24 & 16 & 17 & Switzerland & 9.5 & 21 & 17 \\
\hline Brazil & 20.5 & 24.5 & 18 & Macedonia & 36.5 & 20 & 18 \\
\hline Macedonia & 30 & 17 & 19 & Tunisia & 20 & 17 & 19 \\
\hline Slovenia & 14 & 19 & 20 & Belarus & 24.5 & 16 & 20.5 \\
\hline Angola & 20.5 & 30 & 21.5 & Portugal & 14 & 12 & 20.5 \\
\hline Czech Republic & 18.5 & 24.5 & 21.5 & Greece & 22.5 & 25.5 & 22 \\
\hline Bulgaria & 30 & 27 & 27 & Romania & 22.5 & 13.5 & 23.5 \\
\hline China & 30 & 28 & 27 & Ukraine & 33 & 23 & 23.5 \\
\hline Egypt & 27 & 30 & 27 & Cuba & 36.5 & 34.5 & 26 \\
\hline Japan & 24 & 24.5 & 27 & Korea & 20 & 34.5 & 26 \\
\hline Lithuania & 22 & 15 & 27 & Lithuania & 36.5 & 34.5 & 26 \\
\hline Portugal & 17 & 21 & 27 & Austria & 16 & 23 & 28 \\
\hline Slovakia & 16 & 24.5 & 27 & Slovakia & 17 & 27.5 & 29 \\
\hline The Dominican Republic & 24 & 30 & 27 & Argentina & 29 & 27.5 & 34 \\
\hline \multirow[t]{8}{*}{ Turkey } & 27 & 20 & 27 & Brazil & 27 & 23 & 34 \\
\hline & & & & Iran & 27 & 34.5 & 34 \\
\hline & & & & Israel & 27 & 30 & 34 \\
\hline & & & & Japan & 30.5 & 34.5 & 34 \\
\hline & & & & Luxemburg & 33 & 34.5 & 34 \\
\hline & & & & Morocco & 33 & 34.5 & 34 \\
\hline & & & & Netherlands & 36.5 & 25.5 & 34 \\
\hline & & & & Turkey & 30.5 & 34.5 & 34 \\
\hline
\end{tabular}


Table 5

Spearman's Rank-Order Correlation for the team level analyses, for women and men.

\begin{tabular}{ccccc}
\hline \multirow{3}{*}{ Women } & $r_{s}$ & $p$ & $\begin{array}{c}\text { Degrees of } \\
\text { freedom }\end{array}$ \\
\hline \multirow{5}{*}{ Men } & Youth vs Junior & 0.86 & 0.00 & 29 \\
& Youth vs Senior & 0.84 & 0.00 & 29 \\
& Junior vs Senior & 0.89 & 0.00 & 29 \\
& Youth vs Junior & 0.83 & 0.00 & 36 \\
& Youth vs Senior & 0.83 & 0.00 & 36 \\
& Junior vs Senior & 0.87 & 0.00 & 36 \\
\hline
\end{tabular}

A

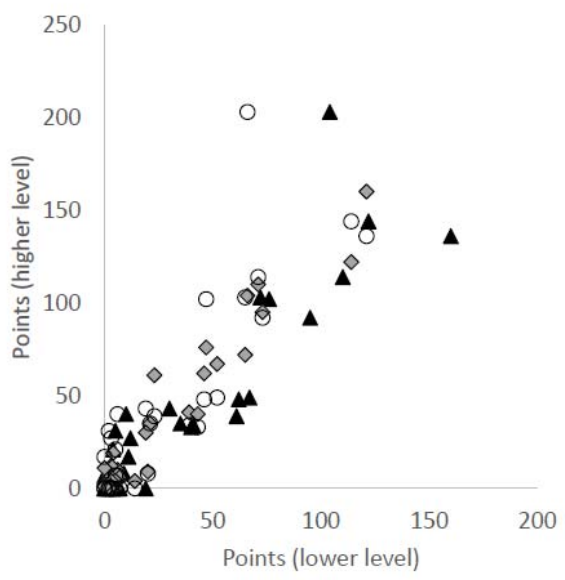

B

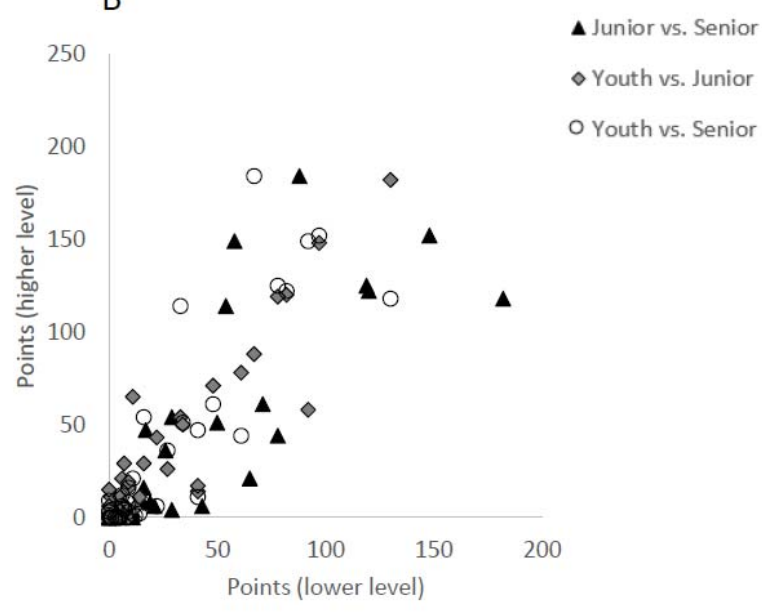

Figure 1

Youth, junior and senior international team results

X-Y plot showing the total points given to each team during the period 1993-2017, for women $(A)$ and men (B). When plotted, the lower-level team (e.g. youth in the youth vs. junior category) is plotted on the $x$-axis. 


\section{Discussion}

The findings of this study demonstrate that players with competitive youth international experience were significantly more likely to have played more junior international matches, compared to players who did not have match experience from the youth international level. Similarly, players who had competitive junior international experience were significantly more likely to have played more senior international matches, compared to players without match experience from the junior international level. However, only in men's handball players with competitive youth international experience were found to be significantly more likely to have played more senior international matches, compared to players who did not have such experience. The correlation between the number of international matches played at the youth and junior international levels and adult success, measured as the number of senior international matches, was either none or weak (0.14-0.35 in women's handball and 0.19-0.48 in men's handball). In addition, the results at the team level in both women's and men's handball revealed a strong relationship between results at the youth, junior and senior international levels.

In their study of players' progression through national squads in women's and men's soccer, volleyball, swimming and judo, Barreiros et al. (2014) showed that many athletes who had been selected to compete at an international level at a young age reappeared later as part of junior and senior national squads. Their results showed that the majority of players continued to compete in junior squads: $58 \%$ of women and $55 \%$ of men, respectively. In our sample, in comparison, $52.5 \%$ of the women's and $48.8 \%$ of the men's youth national team athletes also took part at the junior international level. Barreiros et al. (2014) further reported a $30 \%$ percent progression rate from the youth to the senior international team level, whereas in our sample only $14.4 \%$ of the female and $15.4 \%$ of the male players progressed to the senior international team level from the youth level. While most of the early selected athletes in the study by Barreiros et al. (2014) study were replaced by others when progressing to the next level, the athletes in our study $(81.1 \%$ of Norwegian female and $88.2 \%$ of Norwegian male senior international handball players) had previous competitive experience at either the youth or junior international team level. This finding supports the notion that the athlete development model in Norwegian handball is broad-based, and provides a relatively large number of players with exposure to international team activities at the youth and junior international team levels (Bjørndal et al., 2015).

Previous studies have shown that youth and junior national team activities provide highly influential developmental experiences for youth elite handball players in Norwegian women's handball (Bjørndal and Ronglan, 2017). The Bjørndal et al.'s (2016) longitudinal study of pathways to the elite level among Norwegian women handball players with international youth and junior team experience revealed that elite players had been more involved in youth and junior national team activities than non-elite ones. However, the study showed that there was more variation within the group of youth national team players that progressed to the elite level than there were differences between groups of players that progressed to elite, near-elite and non-elite levels. The authors therefore concluded that using average values to explain highly variable pathways was of little value and could be potentially misleading. Moreover, successful transitions from the junior to the senior elite level among Norwegian handball players with youth and junior national team experience have been shown to be partly dependent on coincidental factors that are outside of athletes' control, such as injuries or transfers of other players (Bjørndal et al., 2017).

Findings from this study can be important in terms of their implications for policies related to elite sports systems and to athlete development in two ways. Firstly, the results do not support the 'more-equals-better' logic of many modern elite sport systems in which athlete talent development is seen as dependent on higher levels of exposure to talent development initiatives. Bahr (2014) suggested that over-exposing talented youth athletes to extra development initiatives could put them in imminent danger by greatly increasing the risk of overuse and injuries. Both acute and chronic injuries have been shown to be an inherent consequence of the talent development model of Norwegian handball (Bjørndal and 
Ronglan, 2017). The international schedule for all youth, junior and senior teams is regulated by the European Handball Federation and qualifications for youth and junior championships are usually played in January and/or April. The Norwegian international teams prepare for these competitions in advance by practicing together and playing international matches. Most importantly, if the team is qualified, all international youth and junior championships in handball are scheduled in the middle of the summer holidays, in what would normally be the off-season period for the athletes. This runs counter to what is known about the importance of training periodisation: the combination of competitions and required preparation strongly increases exposure to highintensity training and match activities. At the same time, it does not allow the only break available to players between their standard competitive seasons. In such a system, a youth elite handball player could progress through a 4to 5-year-long season without having any significant break from organised practice and competitions. This kind of year-round exposure to a single sport may significantly increase the risk of injuries (Myer et al., 2015).

It is important to recognise that schedules of this kind in international youth and junior competition can be potentially counterproductive. Less emphasis should be placed on optimal preparation for championships, and more on facilitating long-term development through, for instance, educating athletes and by providing high-quality experiences. Alternative approaches that focus less on the frequency of activities, and more on the quality of the processes involved are important because international team athletes have already been shown to be overexposed to talent development initiatives (Bjørndal et al., 2017). It is encouraging that the Norwegian youth and junior international handball teams already provide athletes with valuable knowledge about physical and mental training, nutrition and recovery, high-quality motivational experiences, as well as a national and international frame of reference for development (Bjørndal and Ronglan, 2017).

Secondly, the results of this study indicate that international team activities at the youth and junior levels can be successfully utilised as a tool for athlete's development. The ways in which this can be achieved will be influenced by the characteristics of particular national settings. This finding could be especially valuable in the Norwegian context, because the Norwegian Handball Federation typically facilitates the identification of a broad base of players rather than a selected few, and players can become more or less involved during the youth and junior international stages. The talent development model in Norwegian handball has been described as heterarchical because it has no strong centralised structure responsible for talent development. The Norwegian National Handball Federation, for example, is just one of several key parties in the development of talented youth players (Bjørndal et al., 2015). Other countries, especially outside Scandinavia, may have more centralised and normative talent development systems, and this may strongly influence both the selection of players to international teams and the developmental activities provided (Andersen and Ronglan, 2012).

Norwegian handball is characterised by a high number of registered youth players under the age of 17 years (85000, of which two-thirds are female) and this may also influence the structure and appropriateness of talent identification to international teams. There is little evidence that early selection to talent development initiatives is either efficient or necessary, particularly within team sports (Davids et al., 2013). A re-occurring problem in talent identification is the relative age effect, which is the phenomenon of skewed birth date distributions in athletic populations and the overrepresentation of athletes born close to age cut-off dates in particular sports (Abbott et al., 2005). Studies have shown that the extent of the relative age effect varies (see, for example Goldschmied et al., 2011) and that reporting the degree of prevalence may be affected by the method of analysis used (Delorme et al., 2010). However, several studies have noted a strong selection bias in competitive handball (see, for example Baker et al., 2009; Schorer et al., 2010). Relative age effect has been shown to be strong across selections to international teams in handball, especially at the youth and junior international levels (Aguilar et al., 2012; Aguilar et al., 2017; Schorer et al., 2009; Sánchez-Rodríguez et al., 2013). Thus, the lack of more structured talent identification in Norwegian handball may 
help to counteract the negative consequences associated with early attempts to identify talent (Bjørndal et al., 2015). Within our sample, 32 female players and 34 male players per agecategory were, on average, given competitive experience at either the youth or junior international team level for their representative team. However, more research is needed to uncover whether there is a trend in Norway, relative to other countries, towards giving more players competitive experience in international handball at the youth and junior levels.

The strong correlations between team rankings in the team level analyses (Table 5) indicate that handball nations tend to produce strong or weak results across the whole spectrum of youth, junior and senior international competitions. However, caution is needed when interpreting this finding from our study because the team analysis did not allow us to assess the causality of the relationship. This means that it is unclear whether any causal relationship exists and, if it does exist, the direction in which the causation occurs. Finally, the results did not reveal the mechanisms by which any such a relationship might work.

It is possible to suggest that achieving significant results at the youth and junior levels in Norway could lead to the achievement of better results at the senior level. However, several studies have highlighted the apparent absence of a relationship between early performance and adult expertise at the individual level (Barreiros et al., 2014; Gulbin et al., 2013; Vaeyens et al., 2009; Renshaw et al., 2012). Alternatively, it could be argued that having successful senior international teams could lead to a positive trickle-down skills effect to other levels, as well as better results and stronger recruitment. In reality, patterns of performance across different age levels can be unclear and inconsistent. Between 1993-2017 Denmark's men's handball teams, for example, were ranked first in both the youth and junior championships, yet the country was ranked sixth at the senior level. In future studies, contextsensitive in-depth investigations of cases like these may provide valuable insights. Results from team result rankings have, in themselves, little explanatory value, but may be useful in generating new and novel hypotheses for further research.

Our study provides empirical evidence of the association between competitive international participation and team success at the youth, junior and senior levels. These findings could help to influence elite sport policy in handball and inform future topics of research. The results could also contribute to a better understanding of how elite sport systems both facilitate and restrain athlete development within specific sporting contexts and cultures. However, deeper empirical insights are needed about the effectiveness of systems designed to develop and foster talented athletes. International competitive experience at the youth and junior levels appears to shape success at the senior international level in handball, although the amount of involvement seems to be of less importance. Greater emphasis should be placed on unravelling the qualitative factors related to the experience and influence of youth and junior international team activities on learning and development throughout adolescence. More research is needed to uncover the mechanisms through which international youth and junior international team activities influence athlete's development. There is a need for longitudinal studies to trace and compare the development of athletes involved in national teams throughout their adolescence. This might provide the level of nuance and context needed to further develop theory and practice in athletes' development, and could potentially deepen the understanding of the mechanisms involved in facilitating elite sport success at the adult level.

\section{References}

Abbott A, Button C, Pepping G-J, Collins D. Unnatural selection: Talent identification and development in sport. Nonlinear Dynamics, Psychology, and Life Sciences, 2005; 9: 61-88

Aguilar ÓG, García MS, Marín JC, Fernández Romero JJ. Influence of a Player's Year of Birth on the Chances of Being Talent-Spotted in International Women's Handball. Apunts: Educació Física i Esports, 2012: 5460 
Aguilar ÓG, García MS, Romero JJF. Constituent year effect in international handball at high level. Journal of Human Sport \& Exercise, 2017; 12: 316-324

Andersen SS, Houlihan B, Ronglan LT. Systems and the development of elite athletes. In: Andersen SS, Houlihan B and Ronglan LT (eds) Managing elite sport systems. Oxon, UK: Routledge, 3-15; 2015

Andersen SS, Ronglan LT. A comparative perspective on Nordic elite sport: filling a gap. Nordic Elite Sport: Same ambitions - Different tracks. Oslo: Universitetsforlaget, 259-284; 2012

Bahr R. Demise of the fittest: are we destroying our biggest talents? Brit J Sport Med, 2014; 48: 1265-1267

Bailey R. Talent development and the luck problem. Sport, Etichs and Philosophy, 2007; 1: 367-377

Bailey R, Collins D. The Standard Model of Talent Development and Its Discontents. Kinesiology Review, 2013; 2: 248-259

Baker J, Schorer J, Cobley S, Bräutigam H, Büsch D. Gender, depth of competition and relative age effects in team sports. Asian Journal of Exercise \& Sports Science, 2009; 6: 1-7

Barreiros A, Côté J, Fonseca AM. From early to adult sport success: Analysing athletes' progression in national squads. Eur J Sport Sci, 2014; 14: 178-182

Bjørndal CT, Andersen SS, Ronglan LT. Successful and unsuccessful transitions to the elite level: The youth national team pathways in Norwegian handball. International Journal of Sports Science \& Coaching, 2017; 13: 533-544

Bjørndal CT, Ronglan LT. Orchestrating talent development: youth players' developmental experiences in Scandinavian team sports. Sports Coaching Review, 2017: 1-22

Bjørndal CT, Ronglan LT, Andersen SS. Talent development as an ecology of games: a case study of Norwegian handball. Sport, Education and Society, 2015; 22: 864-877

Bjørndal CT, Ronglan LT, Andersen SS. The diversity of developmental paths among youth athletes: A 3year longitudinal study of Norwegian handball players. Talent development \& Excellence, 2016; 8: 20-32

Costello JT, Bieuzen F, Bleakley CM. Where are all the female participants in Sports and Exercise Medicine research? Eur J Sport Sci, 2014; 14: 847-851

Davids K, Araújo D, Vilar L, Renshaw I, Pinder R. An Ecological Dynamics Approach to Skill Acquisition: Implications for Development of Talent in Sport. Talent Development \& Excellence, 2013; 5: 21-34

De Bosscher V, De Knop P, Van Bottenburg M, Shibli S. A Conceptual Framework for Analysing Sports Policy Factors Leading to International Sporting Success. European Sport Management Quarterly, 2006; 6: $185-215$

Delorme N, Boiché J, Raspaud M. Relative age effect in elite sports: Methodological bias or real discrimination? Eur J Sport Sci, 2010; 10: 91-96

DiFiori JP, Benjamin HJ, Brenner JS, Gregory A, Jayanthi N, Landry GL, Luke A. Overuse injuries and burnout in youth sports: a position statement from the American Medical Society for Sports Medicine. Brit J Sport Med, 2014; 48: 287-288

Dineen LC, Blakesley BC. Algorithm AS 62: Generator for the sampling distribution of the Mann-Whitney U statistic. Appl Stat-J Roy St C, 1973; 22: 269-273

Ericsson KA, Krampe RT, Tesch-Roemer C. The role of deliberate practice in the acquisition of expert performance. Psychol Rev, 1993; 100: 363-406

Goldschmied N, Cobley S, Wattie N, Baker J, McKenna J. No Evidence for the Relative Age Effect in Professional Women's Sports. Sports medicine (Auckland, N.Z.), 2011; 41: 87-90

Gulbin JP, Weissensteiner JR, Oldenziel K, Gagné F. Patterns of performance development in elite athletes. Eur J Sport Sci, 2013; 13: 605-614

Luteberget LS, Spencer M. High-Intensity Events in International Women's Team Handball Matches. Int J Sports Physiol Perform, 2017; 12: 56-61

Malina RM. Early sport specialization: roots, effectiveness, risks. Curr Sports Med Rep, 2010; 9: 364-371

Myer GD, Jayanthi N, Difiori JP, Faigenbaum AD, Kiefer AW, Logerstedt D, Micheli LJ. Sport Specialization, Part I: Does Early Sports Specialization Increase Negative Outcomes and Reduce the Opportunity for 
Success in Young Athletes? Sports Health, 2015; 7: 437-442

Povoas SC, Ascensao AA, Magalhaes J, Seabra AF, Krustrup P, Soares JM, Rebelo AN. Physiological demands of elite team handball with special reference to playing position. Journal of strength and conditioning research, 2014; 28: 430-442

Renshaw I, Davids K, Phillips E, Kerhervé H. Developing talent in athletes as complex neurobiological systems. In: Baker J, Cobley S and Schorer J (eds). Talent identification and development in sport: international perspectives. Oxon: Routledge, 64-80; 2012

Ronglan LT. Elite sport in Scandinavian welfare states: legitimacy under pressure? International Journal of Sport Policy and Politics, 2014; 7: 1-19

Sánchez-Rodríguez C, Grande I, Sampedro J, Rivillagarcía J. Is the date of birth an advantage/ally to excel in handball? Journal of Human Sport \& Exercise, 2013; 8: 754-760

Schorer J, Baker J, Lotz S, Büsch D. Influence of early environmental constraints on achievement motivation in talented young handball players. Int J Sport Psychol, 2010; 41: 42-57

Schorer J, Cobley SP, Büsch D, Bräutigam H, Baker J. Influences of competition level, gender, player nationality, career stage and playing position on relative age effects. Scand J Med Sci Spor, 2009; 19: 720730

Silva A, Barreiros A, Fonseca AM. Do the international athletes of the national youth teams are the same in the Senior National team? A study focused on the Portuguese handball throughout more than two decades. E-balonmano.com: Journal of Sports Science / Revista de Ciencias del Deporte, 2015; 11: 131-142

Steffen K, Engebretsen L. More data needed on injury risk among young elite athletes. Brit J Sport Med, 2010; 44: $485-489$

Vaeyens R, Gullich A, Warr CR, Philippaerts R. Talent identification and promotion programmes of Olympic athletes. J Sport Sci, 2009; 27: 1367-1380

Wagner H, Finkenzeller T, Würth S, von Duvillard SP. Individual and Team Performance in Team-Handball: A Review. Journal of Sports Science \& Medicine, 2014; 13: 808-816

\section{Corresponding author:}

\section{Christian Thue Bjørndal}

Department of Coaching and Psychology,

The Norwegian School of Sport Sciences,

Sognsveien 220, 0863 Oslo, Norway.

Email: christian.bjorndal@nih.no 